\title{
Effect of solidification rate on martensitic transformation behavior and adiabatic magnetocaloric effect of $\mathrm{Ni}_{50} \mathrm{Mn}_{35} \mathrm{In}_{15}$ ribbons
}

C.O. Aguilar-Ortiz ${ }^{\text {a,b, }}$, J. P. Camarillo-García a ${ }^{\text {, J. Vergara }}{ }^{\text {a }}$, P. Álvarez-Alonso ${ }^{\text {c }}$, D. Salazar ${ }^{\text {b }}$, V.A. Chernenko ${ }^{\text {b, d }}$, H. Flores-Zúñiga a

a División de Materiales Avanzados, Instituto Potosino de Investigación Científica y Tecnológica A.C., San Luis Potosí 78216, Mexico

${ }^{\mathrm{b}}$ BCMaterials \& University of Basque Country (UPV/EHU), Bilbao 48080, Spain

${ }^{\mathrm{c}}$ Departamento de Física, Universidad de Oviedo, Oviedo 33007, Spain

d Ikerbasque, Basque Foundation for Science, Bilbao 48013, Spain

Corresponding author:

aguilar.ortiz.c.o@gmail.com

\begin{abstract}
$\mathrm{Ni}_{50} \mathrm{Mn}_{35} \mathrm{In}_{15}$ compound has become an archetype for investigating the functional properties of metamagnetic shape memory alloys. We have fabricated $\mathrm{Ni}_{50} \mathrm{Mn}_{35} \mathrm{In}_{15}$ melt spun ribbons to study the crystal structure, microstructure, martensitic transformation, magnetic properties and magnetocaloric effect as a function of the ribbon solidification rate controlled by the wheel speed. We have found that an increase of the cooling rate refines the alloy grain size, which, in turn, influences the chemical order of austenite phase and functional properties: ribbons produced at low wheel speed $(10,20$ and $30 \mathrm{~m} / \mathrm{s})$ present majorly L $2{ }_{1}$ structure associated with higher magnetic entropy change, $\Delta S_{\mathrm{M}}$ (up to $18.6 \mathrm{~J} / \mathrm{kgK}$ for a magnetic field change of $\mu_{0} \Delta H=5 \mathrm{~T}$ ) and Curie temperatures of austenite, $T_{\mathrm{C}}{ }^{\mathrm{A}}$, and martensite, $T_{\mathrm{C}}{ }^{\mathrm{M}}$ $\left(T_{\mathrm{C}}^{\mathrm{A}}=309 \mathrm{~K}\right.$ and $\left.T_{\mathrm{C}}^{\mathrm{M}}=199 \mathrm{~K}\right)$ compared with the B2-ordered single phase ribbons $\left(\Delta S_{\mathrm{M}}=\right.$
\end{abstract}


$11.3 \mathrm{~J} / \mathrm{kgK}$ for $\left.\mu_{0} \Delta H=5 \mathrm{~T} ; T_{\mathrm{C}}^{\mathrm{A}}=293 \mathrm{~K} ; T_{\mathrm{C}}^{\mathrm{M}}=178 \mathrm{~K}\right)$ obtained at higher cooling rates $(40$ and $50 \mathrm{~m} / \mathrm{s}$ ). Besides, we have also observed a correlation between the grain size reduction and a shift of the martensitic transformation to lower temperatures. Direct measurements of the adiabatic temperature change have been performed during both the first- and secondorder phase transitions. The results disclose the correlation between structural and magnetic properties of the ribbon and the wheel speed, which opens an innovative tool to adjust the transformation characteristics and magnetocaloric properties through the solidification rate control.

Keywords: metamagnetic shape memory ribbons; chemical order; adiabatic magnetocaloric effect; solidification rate.

\section{Introduction}

Caloric effects have received special attention for solid-state refrigeration due to the high cooling efficiency and their environmental friendly character. The caloric effects are characterized by adiabatic temperature change, $\Delta T_{\text {ad, }}$, and isothermal entropy change when the external stimulus is applied or released. Depending on the external force applied to the system, different caloric effects can be present: the elasto- (eC), baro- (BC), electro- (EC) and magnetocaloric (MC) effects, which are driven by uniaxial stress, hydrostatic pressure, electric and magnetic field, respectively [1-4].

The MC is, by far, the most studied caloric effect, and the focus has been placed on several families of alloys. Among them, the Heusler-type Ni-Mn-X ( $X=S n$ or In) and their derivatives, named as metamagnetic shape memory alloys (MetaMSMAs), have attracted a considerable attention because they display giant inverse $\mathrm{MC}$ effect, which means that the 
application of a magnetic field under isothermal conditions produces an increase of magnetic entropy, whereas its application under adiabatic conditions causes a reduction of the temperature with values of the magnetic entropy change, $\Delta S_{\mathrm{M}}$, that can be higher than 20 $\mathrm{J} / \mathrm{kgK}$ for applied magnetic fields up to $5 \mathrm{~T}$, as a consequence of the magnetic-field induced inverse martensitic transformation from a magnetically-weak martensite to a ferromagnetic austenite [5-14]. The possibility to adjust the martensitic transformation (MT) in a desirable temperature interval (including room temperature) by small changes in the composition and the high sensitivity of magnetic properties to variations in the composition, microstructure, alloying elements and/or chemical order [15-18] (and therefore the MC effect itself) have put forward the MetaMSMAs as promising candidates for future applications in the solidstate magnetic refrigeration [10,19-21]. This technology requires fast heat exchange between the MC material and the fluid heat exchanger which can be achieved using materials with large surface-to-volume ratio such as ribbons fabricated by melt-spinning.

MC effect has been studied in MetaMSMA melt-spun ribbons by assessing $\Delta S_{\mathrm{M}}[22]$, or $\Delta T_{\text {ad }}$ values from heat capacity dependences under magnetic field (see, e.g., [23]). Whereas there exists a number of reports on the direct measurements of $\Delta T_{\mathrm{ad}}$ in the bulk MetaMSMAs [20,24-26], the $\Delta T_{\text {ad }}$ data for MetaMSMAs ribbons are scarce due to the experimental difficulty to measure the adiabatic temperature change in ribbons $[27,28]$.

Obviously, the melt spinning technique is advantageous for fabricating ready-shaped MC materials. On the other hand, a melt-spun processing, resulting in a highly refined grain structure due to the high cooling rate (typically, $10^{4}-10^{6} \mathrm{~K} / \mathrm{s}$ ) [29], can alter the physical characteristics of the alloys. It has been pointed out that high cooling rates can stabilize the austenite phase with the high temperature B2 ordered structure instead of the highly ordered 
L2 1 [30,31]. It was shown that the reduction of grain size with the increment of wheel speed rises the density of crystal defects, which, in turn, reduces the MT temperature and limits the size of martensitic variants in Ni-Mn-Sn, Ni-Mn-Ga and Fe-Ni-P-B [32-34]. The grain size has also a similar effect on the MT temperatures in Ni-Mn-Sn-Co ribbons, although its enlargement is observed with increasing of the wheel speed in this case [30]. It was also observed that the coarsening of the grain structure by annealing causes an increase of the MC response (see, for instance $[21,35]$ ).

The aim of the present work is to perform a systematic study of the influence of solidification rate on the martensitic transformation behavior, magnetism, chemical order, microstructure, and isothermal and adiabatic $\mathrm{MC}$ properties of the $\mathrm{Ni}_{50} \mathrm{Mn}_{35} \mathrm{In}_{15}$ ribbons. The selected compound is a well-known model object of MetaMSMAs. The ribbons have been received by a melt spinning technique in a wide range of linear wheel speed varying from 10 to $50 \mathrm{~m} / \mathrm{s}$.

\section{Experimental}

Polycrystalline $\mathrm{Ni}_{50} \mathrm{Mn}_{35} \mathrm{In}_{15}$ ingot was prepared by arc melting of high purity metals $(>99.9 \%)$ in argon atmosphere. Alloy was re-melted several times to improve homogeneity. The ribbons were fabricated by melting pieces of as-cast ingots and then melt-spun at different linear speed (WS) of the copper wheel, from 10 to $50 \mathrm{~m} / \mathrm{s}$, under Ar pressure. Obtained melt-spun ribbons are labeled as V10 $(10 \mathrm{~m} / \mathrm{s}), \mathrm{V} 20(20 \mathrm{~m} / \mathrm{s}), \mathrm{V} 30(30 \mathrm{~m} / \mathrm{s}), \mathrm{V} 40$ $(40 \mathrm{~m} / \mathrm{s})$ and V50 $(50 \mathrm{~m} / \mathrm{s})$, respectively. The microstructure of as-spun ribbons was examined at $223 \mathrm{~K}$ and $323 \mathrm{~K}$ by a scanning electron microscope (SEM) Hitachi TM3000. The energy dispersive X-ray spectroscopy (EDS) revealed an average composition of $\mathrm{Ni}_{51} \mathrm{Mn}_{35} \operatorname{In}_{14}$ for all the ribbons with an uncertainty of \pm 1 at. $\%$, estimated by the standard 
deviation using up to ten different measurements. No composition difference is found between the free surface (which was not in contact with copper wheel) and the surface in contact with the wheel. The cross-section of ribbons was analyzed by means of a Nikon Eclipse MA200 optical microscope. The MT temperatures, enthalpy changes $(\Delta H)$ and MT entropy changes $(\Delta S)$ were determined from the differential scanning calorimetry (DSC) measurements performed in a DSC TA-Q200 instrument at cooling/heating ramps of 5 $\mathrm{K} / \mathrm{min}$. Details of determination of $\Delta H$ and $\Delta S$ can be found elsewhere [16]. Particularly, $\Delta H$ for endothermic and exothermic reactions in DSC curves were calculated by using Peak and Baseline analysis in OriginPro 9, and then the average values were taken as total transformation enthalpies [36].

The crystal structures and lattice parameters were determined by X-ray diffraction (XRD) at $333 \mathrm{~K}$ employing a Bruker D8 Advance diffractometer $(30 \mathrm{kV}$ and $20 \mathrm{~mA}$, $\lambda_{\mathrm{Cu}}=1.5418 \AA$ ). The Rietveld structural refinement was performed using the FullProf suite [37].

The thermomagnetization curves, $M(T)$, were measured using a vibrating sample magnetometer Cryogenic Ltd CFMS between $5 \mathrm{~K}$ and $320 \mathrm{~K}$ and fields up to $9 \mathrm{~T}$. The magnetic field, $\mu_{0} H$, was applied along the ribbon length to minimize a demagnetizing field effect. The Curie temperatures of martensitic $\left(T_{\mathrm{C}}{ }^{\mathrm{M}}\right)$ and austenitic $\left(T_{\mathrm{C}}{ }^{\mathrm{A}}\right)$ phases were extracted from $M(T)$ curves by the conventional tangential method [38]. Adiabatic measurements of the magnetocaloric effect were carried out under $\mu_{0} \Delta H=1.95 \mathrm{~T}$ using the set-up described in Ref [39]. In these measurements, to overcome the difficulties with measuring $\Delta T_{\text {ad }}$ values in a single ribbon, a stack of ribbons with a typical weight of $\sim 20 \mathrm{mg}$ was used, and a thin T-type thermocouple with $0.08 \mathrm{~mm}$ in diameter was placed inside the 
stack. No thermal conductive paint was used. The resolution of $\Delta T_{\text {ad }}$ measurements was $\sim 0.1$ K. To avoid the effect of thermal hysteresis of MT, the measurements protocol for the heating ramp was as follows: (i) cooling of the sample below $T_{\mathrm{MF}}$ (martensite finish temperature) assuring that the material is in martensitic phase; (ii) setting of the desired sample temperature; and (iii) placing of the sample into the magnetic field once it was thermally equilibrated. Measurements in the cooling ramp were performed in an analogous way, but the temperature in step (i) was above $T_{\mathrm{AF}}=343 \mathrm{~K}$ (austenite finish temperature). In both cases, the cycle was repeated several times after the step (iii).

\section{Structural characterization}

\subsection{Crystal structure}

Fig. 1 shows the X-ray diffraction patterns collected at $333 \mathrm{~K}$ on the as-spun ribbons. The diffraction peaks were indexed according to the cubic L21- and B2-ordered crystal structures. Note that the two peaks surrounding the main diffraction peak are related to a Pt sample holder. To distinguish between the L2 1 and B2 structures, one can use the characteristic peak (111) of the L21-ordered structure, which allows us to conclude that the ribbons V10, V20, and V30 consist of a mixture of both phases, whereas V40 and V50 exhibit B2 atomic order only. Rietveld analysis of the diffraction patterns confirms the coexistence of L2 1 and B2 structures in the ribbons prepared at the wheel speeds between $10 \mathrm{~m} / \mathrm{s}$ and 30 $\mathrm{m} / \mathrm{s}$, and the existence of a unique B2 structure in V40 and V50 specimens, as summarized in Table 1, where lattice unit cell parameters can be found as well. Note that the B2 structure implies the first neighbors atomic order only, whereas L2 1 includes also the second 
neighbors. In the case of bulk Ni50 $\mathrm{Mn}_{35} \mathrm{In}_{15}$ alloy, B2 order is normally observed above $960 \mathrm{~K}$ $[40,41]$, while in ribbons V40 and V50 it exists at the room temperature.

\subsection{Microstructure}

The microstructure of the free surface of as-spun ribbons was analyzed at different temperatures. At $323 \mathrm{~K}$, the surface exhibits granular microstructure with different grains size and grains shape. In Fig. 2, SEM images for V10 (a), V30 (b), and V50 (c) ribbons are presented showing the grain refinement effect produced by the increment of WS. The microstructure analyzed by the electron backscattering imaging does not reveal any secondary phases, in good agreement with the X-ray diffraction analysis. Fig. 2 (d) depicts the microstructure, at $223 \mathrm{~K}$, of the V10 ribbon surface that was in contact with the copper wheel. At this temperature, the specimen presents well-resolved martensitic variants inside the grains, which spread across the grain boundaries as well. Similar results have been reported on Ni-Mn-Sn-Co, which were associated to the small angle boundaries characterized by a low energy $[30,42]$. The microstructure reflects a cobweb-like grain growth of few grains surrounded by elongated grains, which might be related with the different grain growth dynamics during rapid solidification.

Inset to Fig. 3 shows a typical image of the cross-section of studied NiMnIn ribbons. The ribbons present a columnar-like grain structure along the perpendicular direction to the ribbon plane, as this corresponds to the main heat transfer direction during rapid solidification $[35,43,44]$. Note the presence of a layer with refined grain dimensions in the free surface, which indicates that the high cooling rate in the free side of the ribbons limits the kinetics of the grain growth.

Fig. 3 shows the dependence of the average thickness and grain size (GS) ribbons on the linear wheel speed. The average grain size, obtained from the SEM images of non-contact 
surface, decreases in two linear regimens, the first one corresponds to a mixture of B2 and L21 structures in V10, V20 and V30 ribbons, the second one to B2 structure in V30 and V50 ribbons. In turn, the ribbon thickness, measured from the optical image, decreases exponentially when the wheel speed increases.

\section{Martensitic transformation}

Fig. 4 shows DSC curves for as-spun ribbons obtained at different WS, which exhibit characteristic endothermic and exothermic peaks produced by MT. The peak associated to the forward transformation during cooling from austenite to martensite is wider than the peak of reverse transformation, which can be associated with a certain internal friction of phase boundary motion, since the boundary motion is hampered by crystal defects or residual stresses produced during rapid quenching from the melt. The thermal hysteresis is about $13 \mathrm{~K}$

for the ribbons, whereas the minimum thermal hysteresis for bulk alloys has been reported to be equal to $4 \mathrm{~K}$ [14]. Furthermore, it is worth noting that the martensitic transformations in the ribbons occur at lower temperatures (Table 1) in comparison to the bulk alloy [8,39].

The inset to Fig. 4 demonstrates that quasi-equilibrium MT temperature, $T_{0}$, versus wheel speed, where $T_{0}$ corresponds to the middle of the MT hysteresis loop, exhibits a linear lowering with the kink correlated with the similar trend of the grain size in Fig. 3. The initial slope $\mathrm{d} T_{0} / \mathrm{d}(\mathrm{WS})$ is equal to $-0.4 \mathrm{~K} / \mathrm{m} \mathrm{s}^{-1}$, which is larger than that reported for Ni-Mn-In-Si ribbons $\left(-0.2 \mathrm{~K} / \mathrm{m} \mathrm{s}^{-1}\right)$ [31]. The kink, seems, establishes a limit of WS needed to get pure B2 ordered phase. As the inset in the Fig. 4 shows the average transformation entropy decreases linearly as a function of WS, from $27.7 \mathrm{~J} / \mathrm{kgK}$ for $\mathrm{V} 10$ to $23.0 \mathrm{~J} / \mathrm{kgK}$ for $\mathrm{V} 50$ (Table 1 ).

\section{Magnetic properties}

\subsection{Thermomagnetization curves}


Fig. 5(a) depicts the magnetization versus temperature curves for all ribbons measured in zero-field cooling (ZFC), field cooling (FC), and field heating $(\mathrm{FH})$ protocols (see Ref. [16] for details) recorded in the temperature range between $5 \mathrm{~K}$ and $320 \mathrm{~K}$ at low applied magnetic field $(10 \mathrm{mT})$. Several anomalies reflect the different phase transitions occurring in the specimens: on cooling, the magnetization increases due to ferromagnetic ordering of austenite followed by the magnetization drop at the forward MT owing to the formation of the magnetically-weak martensite. It increases again as the ferromagnetic order of martensitic phase evolves. On heating, the transitions sequence is reversed. Both $\mathrm{MT}$ and $T \mathrm{C}^{\mathrm{A}}$ shifts to lower temperatures with increasing WS (see Table 1). A decrease of MT temperature needs more detailed discussion (see Sec.7). A decrease of $T_{\mathrm{C}}^{\mathrm{A}}$ can be explained directly in terms of the interplay between B2 and $\mathrm{L} 21$ ordering in ribbons, as it was revealed for bulk Ni-Mn-In alloys exhibiting similar trend which shows that the higher $T_{\mathrm{C}}{ }^{\mathrm{A}}$ corresponds to the higher degree of L2 1 order [45]. Indeed, Table 1 confirms this correspondence between L2 $1 / \mathrm{B} 2$ ratio and $T_{\mathrm{C}}{ }^{\mathrm{A}}$ in the ribbons. The decrease of $T_{\mathrm{C}}^{\mathrm{A}}$ with WS suggests a weakening of ferromagnetic exchange interactions between $\mathrm{Mn}$ atoms due to the modification of the configuration of neighboring atoms and interatomic distances between them when changing from the $\mathrm{L} 21$ to B2 structure.

The splitting $(\Delta M)$ between $\mathrm{ZFC}$ and FC-FH magnetization curves at $5 \mathrm{~K}$ has been related with ferromagnetic (FM) and antiferromagnetic (AFM) coupling in the martensitic phase [5]. The inset to Fig. 5(a) shows that $\Delta M$ is large for V10 and then significantly reduces in the interval from V10 to V30, keeping the small values for higher WS. This behavior suggests a link between the atomic disorder inhomogeneity and the FM-AFM interactions. Such a link will be confirmed in the next section by means of the hysteresis loops data at low 
temperatures showing larger magnetic anisotropy for V50 comparatively to V10 and a phenomenon commonly known as the exchange bias.

Fig. 5(b) presents several isofield $M(T)$ curves measured between $220 \mathrm{~K}$ and $320 \mathrm{~K}$ for ribbon V50. The magnetic field reduces more strongly the forward MT temperature than reverse MT, thus increasing the thermal hysteresis and is more noticeable on B2 phase. In fact, V50 ribbon displays the highest thermal hysteresis even with the increment of magnetic field, which reflects a weaker ferromagnetic coupling of Mn-Mn atoms in B2 structure. Note that such characteristics of MT imply a severe drawback for getting a significant MC effect.

\subsection{Exchange bias effect}

It is well known that the atomic order in $\mathrm{Ni}-\mathrm{Mn}-\mathrm{X}$ alloys plays a key role in the interplay between the ferromagnetic (FM) and antiferromagnetic (AFM) interactions of Mn-Mn pairs. Such an interplay comes through the exchange bias (EB) phenomenon, in which the magnetic moments in FM constituent are firmly aligned with the closest moments in the AFM phase below a blocking temperature $\left(T_{\mathrm{B}}\right)$ due to exchange anisotropy. Above $T_{\mathrm{B}}$, the AFM moments lose their ability to align the adjacent FM moments. EB effect is manifested itself through the shift of magnetic hysteresis loop along the field axis $\left(H_{\mathrm{E}}\right)$ and the increment of coercive field $\left(H_{\mathrm{C}}\right)$. These are given by $H_{\mathrm{E}}=-\left(H_{1}+H_{2}\right) / 2$, and $H_{\mathrm{C}}=\left|\left(H_{1}-H_{2}\right)\right| / 2$, where, $H_{1}$ and $H_{2}$ stand for the left and right field values on the $x$-axis at which the magnetization equals zero in the hysteresis loop [46].

The hysteresis loops were measured at low temperatures for V10 and V50. The protocol is described in a previous work [47]. Fig. 6 presents the magnetic hysteresis loops for V10 (a) and V50 (b) from -0.10 to $0.10 \mathrm{~T}$ at $5 \mathrm{~K}$ and $20 \mathrm{~K}$. The hysteresis loops progressively shift along the negative $H$-axis with the increasing temperature from $5 \mathrm{~K}$ to $20 \mathrm{~K}$, indicating the presence of EB in the sample. In Fig. 6 (c), the values of $H_{\mathrm{E}}$ and $H_{\mathrm{C}}$ are presented for V10 
and V50, and, for the sake of comparison, for the bulk alloy with similar composition taken from Ref. [11]. Note that the $H_{\mathrm{E}}$ and $H_{\mathrm{C}}$ are larger in ribbons than in the bulk. For both ribbons (and for the bulk), the $H_{\mathrm{E}}$ continuously decreases with increasing temperature and almost vanishes at $40 \mathrm{~K}$ for $\mathrm{V} 50$ and $80 \mathrm{~K}$ for $\mathrm{V} 10$. However, $H_{\mathrm{C}}$ for $\mathrm{V} 50$ shows a maximum around $T_{\mathrm{B}}(\sim 40 \mathrm{~K})$, whereas it continuously grows with increasing temperature for V10 and bulk. If the antiferromagnetic phase presents low anisotropy, the AFM moments would let FM moments to be dragged easier resulting in a decrease of $H_{\mathrm{C}}$ below blocking temperature [48].

\section{Adiabatic magnetocaloric effect}

The adiabatic temperature change $\left(\Delta T_{\mathrm{ad}}\right)$ was measured at constant temperatures between $273 \mathrm{~K}$ and $335 \mathrm{~K}$ for magnetic field change from 0 to $1.95 \mathrm{~T}$. Fig. 7 presents the dependences of $\Delta T_{\mathrm{ad}}(T)$ during heating and cooling ramps for the V10, V20 and V40 ribbons. Heating curves show minimum and maximum corresponding to the inverse and conventional MC effects related to MT and ferro-paramagnetic phase transition in austenite, respectively, whereas cooling curves show one peak only, related to the conventional MC effect. Similar results have been obtained for ribbon V30 and bulk alloy (see Ref [8,39] and references therein). These ribbons present an appreciable inverse $\mathrm{MC}$ effect resulting from the magnetic field-induced reverse MT, with maximum values of $\Delta T_{\text {ad }}$ equal to about $-1.1 \mathrm{~K}$ at 298 and $289 \mathrm{~K}$ for V10 and V20, respectively. Ribbons V40 and V50 do not show this effect due to more smeared character of the ferromagnetic transition which can mask a signal produced by MT. Cooling $\Delta T_{\mathrm{ad}}(T)$ curves do not manifest the inverse $\mathrm{MC}$ effect in all the present ribbons 
since the applied magnetic field was not strong enough to induce the reverse MT, due to a significant temperature hysteresis of MT, about $16 \mathrm{~K}$ (Fig. 4).

On the other hand, all ribbons exhibit a conventional MC effect at the ferro-toparamagnetic transition in austenite with maximum value of $\Delta T_{\text {ad }}$ equal to $2.5 \mathrm{~K}$ for $\mathrm{V} 10$ which decreases to about $1.4 \mathrm{~K}$ for V40 (Fig. 7). This evolution can be explained by the already mentioned factor, such as more smeared character of a ferromagnetic transition. The values of $\Delta T_{\mathrm{ad}}=-1.6 \mathrm{~K}$ and $2.0 \mathrm{~K}$ at $\mu_{0} H=1.7 \mathrm{~T}$ corresponding to the first-order $\mathrm{MT}$ and second-order ferromagnetic transition, respectively, reported for the Ni50 $\mathrm{Mn}_{35} \mathrm{In}_{15}$ bulk compound $[8,39]$, are close to the ones measured on the ribbons in the present work.

It has to be reminded that the direct measurements of adiabatic temperature change in melt-spun ribbons is experimentally difficult due to the low sample mass (typically, $\sim 1$ mg) and large surface-to-volume ratio, which enlarges the heat transfer capability [49]. However, the latter factor is the most interesting feature of the materials with this geometry, as it promotes the heat exchange, a desirable characteristic of any possible candidate for solid state refrigeration.

\section{Discussion}

The experimental results indicate that the solidification rate (associated to the wheel speed) has a strong effect on the structure and microstructure of the Ni-Mn-In ribbons, which, in turn, have implications in the shift of MT to lower temperatures and the changes in the magnetic properties. The proportion of L21 structure in the ribbons decreases with the increment of WS to the point that V40 and V50 ribbons present only the B2-ordered structure, as follows from X-ray diffraction analysis. Besides, we have pointed out that the thickness 
of the ribbons decreases exponentially with increasing WS. The ribbon thickness, $d$, linear wheel speed, WS, and the solidification rate, $\mathrm{d} T / \mathrm{d} t$, have been related by means of expressions $d \propto \mathrm{WS}^{\mathrm{k}}$, and $\mathrm{d} T / \mathrm{d} t \propto d^{m}$, respectively, where $k$ is an empirical parameter and $m$ is considered to be close to 3 [33,50]. This functional dependence for Ni-Mn-In-Si ribbons has been identified as $d \propto \mathrm{WS}^{-1.7}$, which implies that the solidification rate increases by two orders of magnitude when the wheel speed raises from 12 to $32 \mathrm{~m} / \mathrm{s}$ [31]. In our case, Ni-MnIn ribbons have been found to present similar behavior described by $d \propto \mathrm{WS}^{-1.05}$, where solidification rate increases by two orders of magnitude for those ribbons in the range from 10 to $50 \mathrm{~m} / \mathrm{s}$. Note that the reduction of the ribbon thickness imposes a limitation to the grain size in the perpendicular direction to the ribbons free surface.

Furthermore, we have found a correlation between the shift of MT to lower temperatures and the grain refinement in our Ni50Mn $35 \mathrm{In}_{15}$ melt spun ribbons (Figs. 3 and 4). Similar behavior was reported for Ni-Mn-Sn system [32], where it was attributed to the stabilization of austenite due to the small grain size that prevents the formation of martensitic variants by limiting their size. According to the EDX analysis the chemical composition of the ribbons can be considered constant. Other factors that can affect the MT temperatures are the elastic strain energy due to the lattice mismatch between austenite and martensite, and the defect structure. The elastic strain energy dominates the transition kinetics and the morphology of martensite [51-53], and has been reported to promote the formation of martensite at lower temperatures [54]. The symmetry conforming behavior of the defect structure can also reduce the martensitic transformation temperatures [55]. One should also mention the role of crystals defects in the nucleation of the martensite phase [56]. 
Despite a correlation between the behavior of $T_{0}, \Delta \mathrm{S}$ and GS (Figs. 3 and 4 ), the influence of GS could be hardly considered as the main reason of the observed effects since, for instance, according to the results of Ref. [57], the small GS span in the present work would generate only few Kelvins change in $T_{0}$, while actual change is much higher. On the other hand, the influence of grain boundaries can be strongly complemented by other crystal defects, such as, e.g., quenched-in vacancies. It is expected that the ribbons prepared with higher cooling rate should exhibit higher concentration of such defects which may result in the occurrence of the internal two-dimensional tensile stress experimentally observed in $\mathrm{Ni}$ Mn-Sn ribbon $[59,60]$. An increasing of the internal two-dimensional stretching stress in the ribbon plane as a function of WS could affect the thermodynamic properties of ribbon in a similar way as the three-dimensional analog in the case of bulk alloys [55], i.e., could reduce $T_{0}$, in line with the results shown in Table 1.

The internal stress is also considered as a reason of the MT smearing [18,57]. Figs. 4 and 5 show that this smearing apparently increases as a function of WS. This means, following to Ref. [61], that transformation entropy should decrease according to the expression: $\Delta S \sim 1 /\left(T_{\mathrm{Ms}}-T_{\mathrm{Mf}}\right)$, in agreement with the results in Table 1 . Note that the relation $\Delta S \sim 1 /\left(T_{\mathrm{C}}^{\mathrm{A}}-T_{0}\right)$, known from Ref. [17], is not found in the present work as can be easily proved using the data from Table 1.

The insight into the magnetic field influence on the transformation behavior and $\mathrm{MC}$ effect, evaluated in this case as the field-induced isothermal entropy change, can be obtained by an analysis of the $M(T)$ curves collected at different applied magnetic fields as, for instance, those plotted in Fig. 5(b) for V50. From such dependences, the MT temperatures have been extracted for all the ribbons and plotted as a function of magnetic field (not shown). 
The linear shift of $T_{0}$ to lower temperatures as a function of magnetic field has been obtained in each specimen. Interestingly, the sensitivity of MT temperature to the applied magnetic field $\left(\mathrm{d} T_{0} / \mathrm{d} \mu_{0} H\right)$ appeared to be dependent on the wheel speed, decreasing from $-2.2 \mathrm{~K} / \mathrm{T}$ for $\mathrm{V} 10$ to $-1.7 \mathrm{~K} / \mathrm{T}$ for $\mathrm{V} 50$ (see Table 1 for details). In fact, we can deduce that the L21 atomic order presents a stronger response to the magnetic field than B2. The combination of large value of $\left|\mathrm{d} T_{0} / \mu_{0} \mathrm{~d} H\right|$ with small thermal hysteresis and phase transition interval of MT are especially relevant to achieve the better reversibility of the inverse magnetocaloric effect at low magnetic field $[14,49,59,60]$.

The magnetic field-induced entropy change $\left(\Delta S_{\mathrm{M}}\right)$ was estimated from $M(T)$ curves at different applied magnetic fields using the Maxwell relationship [10]:

$$
\Delta S_{M}(\mathrm{~T}, \mathrm{H})=S_{M}(\mathrm{~T}, \mathrm{H})-S(\mathrm{~T}, 0)=\int_{0}^{H}\left(\frac{\partial M\left(\mathrm{~T}^{\mathrm{H}} \mathrm{H}^{\mathcal{\prime}}\right)}{\partial \mathrm{T}}\right) d \mathrm{H}^{\prime}
$$

Figs. 8 (a) and (b) display the heating ramps of the temperature dependence of $\Delta S_{\mathrm{M}}$ at different applied magnetic fields for ribbons V10 and V50. The curves exhibit a maximum of $\Delta S_{\mathrm{M}}$ at the inverse $\mathrm{MC}$ effect due to the magnetic field-induced reverse $\mathrm{MT}$, and a minimum corresponding to a conventional $\mathrm{MC}$ effect near $T_{\mathrm{C}}{ }^{\mathrm{A}}$. Note that the temperature dependence of $\Delta S_{\mathrm{M}}$ for V10 (see Fig. 8 (a)) presents a sawtooth-like shape above $5 \mathrm{~T}$ due to the mathematic calculus. At $\mu_{0} \Delta H=5 \mathrm{~T}$, the maximum value of $\Delta S_{\mathrm{M}}$ is $22.3 \mathrm{~J} / \mathrm{kgK}$ for the bulk alloy [11], whereas our ribbons show values up to $18.6 \mathrm{~J} / \mathrm{kgK}$. Fig. 8 (c) depicts the plots of the maximums values on the $\Delta S_{\mathrm{M}}(T)$ curves versus magnetic field up to $9 \mathrm{~T}$ for all the ribbons. As can be expected, the V10 ribbon displays the highest values due to the biggest difference in magnetization between austenite and martensite and sharper MT compared with the other ribbons (e.g., $\Delta S_{\mathrm{M}}$ at $5 \mathrm{~T}$ for $\mathrm{V} 10$ is $\sim 19 \mathrm{~J} / \mathrm{kgK}$, while for $\mathrm{V} 50$ is $\sim 12 \mathrm{~J} / \mathrm{kgK}$ ). It has 
been already shown in literature that $\Delta S_{\mathrm{M}}$ versus $\mu_{0} H$ cannot be linear over the complete magnetic field range, but rather should exhibit some maximum (see Ref. [62] and references therein). That is in line with the results shown in Fig. 8 (c).

Another important parameter for characterization of the MC effect is the relative cooling power (RCP), which corresponds to the heat that the material could interchange with its surroundings during a refrigeration cycle. It is commonly estimated by numerical integrating the area under $\Delta S_{\mathrm{M}}(T)$, where the integration limits are the temperatures at full width half maximum [63]. Fig. 8 (d) represents the RCP as a function of the magnetic field for all studied ribbons. The RCP decreases for higher linear wheel speed, which is a consequence of the observed reduction of the $\Delta S_{\mathrm{M}}$. The values of $\Delta S_{\mathrm{M}}(T)$ and RCP are similar to reported for the as-spun Ni-Mn-Co-Sn ribbons [64].

\section{Summary}

In the present work, the influence of the solidification rate (controlled by a copper wheel linear speed in the range $10-50 \mathrm{~m} / \mathrm{s}$ ) on the martensitic, structural, microstructural, magnetic and magnetocaloric properties of the $\mathrm{Ni}_{50} \mathrm{Mn}_{35} \mathrm{In}_{15}$ (at. \%) melt-spun ribbons was studied. It was observed that the martensitic transformation temperature, $T_{0}$, was reduced as a function of wheel linear speed by $0.4 \mathrm{~K} / \mathrm{m} \mathrm{s}^{-1}$. The chemical order of the cubic austenitic phase, probed by the X-ray diffraction, was found to be changed from a mixture of L2 1 and B2 structures observed in V10-V30 ribbons to a fully B2 structure for V40 and V50. The lattice parameter of cubic phase shows a weak decrease on the wheel speed. The increasing of wheel speed caused a grain refinement effect of austenite, as well as decreasing ribbon thickness correlated with the reduction of $T_{0}$. Curie temperatures of the martensite and 
austenite shift to lower temperatures with increasing linear wheel speed. The magnetocaloric effect was characterized by means of direct and indirect measurements. The indirect method presents maximum of the magnetic field induced entropy change, $\Delta S_{\mathrm{M}}$, equal to $18.6 \mathrm{~J} / \mathrm{kgK}$ at $\mu_{0} \Delta H=5 \mathrm{~T}$ for $\mathrm{V} 10$ ribbon with almost $\mathrm{L} 21$-ordered structure and $16 \mathrm{~J} / \mathrm{kgK}$ for $\mathrm{V} 50$ ribbon with fully B2-ordered structure. The maximum values of directly measured adiabatic temperature change under $\mu_{0} \Delta H=1.9 \mathrm{~T}$ were: $\Delta T_{\mathrm{ad}}=-1.1 \mathrm{~K}$ for the inverse MC effect at MT and $2.5 \mathrm{~K}$ for the conventional MC effect at the Curie temperature of austenite.

By eliminating the $\mathrm{L} 21$ order, the solidification rate influences the ferroantiferromagnetic coupling in the ribbons whereby a well pronounced exchange bias effect was observed in the ribbons formed at the highest wheel speed. The disclosed in the present work correlation between structural and magnetic properties of the ribbons and the wheel speed opens an innovative tool to tailor the transformation characteristics and magnetocaloric properties through the solidification rate control.

\section{Acknowledgements}

The financial support from CONACYT Mexico CB 157541, Asturias Government, Spain (FC-15-GRUPIN14-037 245) and the Spanish Ministry of Economy and Competitiveness (MAT2014-56116-C4-3-4-R) is acknowledged. The authors thank to B. A. Rivera Escoto and A. I. Peña Maldonado from LINAN laboratory in IPICYT and I. Orue and A. Larrañaga from SGIker (UPV/EHU, GV/EJ, ESF) for technical support.

\section{References}

[1] L. Mañosa, D. González-Alonso, A. Planes, E. Bonnot, M. Barrio, J.-L. Tamarit, S. Aksoy, M. Acet, Giant solid-state barocaloric effect in the Ni-Mn-In magnetic shape- 
memory alloy, Nat. Mater. 9 (2010) 478-481. doi:10.1038/nmat2731.

[2] S. Crossley, N.D. Mathur, X. Moya, New developments in caloric materials for cooling applications, AIP Adv. 5 (2015) 067153. doi:10.1063/1.4922871.

[3] A. Chauhan, S. Patel, R. Vaish, C.R. Bowen, A review and analysis of the elastocaloric effect for solid-state refrigeration devices: Challenges and opportunities, MRS Energy Sustain. 2 (2015) E16. doi:10.1557/mre.2015.17.

[4] O. Tegus, E. Brück, K.H.J. Buschow, F.R. de Boer, Transition-metal-based magnetic refrigerants for room-temperature applications, Nature 415 (2002) 150-152.

doi:10.1038/415150a.

[5] T. Krenke, M. Acet, E.F. Wassermann, X. Moya, L. Mañosa, A. Planes, Ferromagnetism in the austenitic and martensitic states of Ni-Mn-In alloys, Phys. Rev. B. 73 (2006) 174413. doi:10.1103/PhysRevB.73.174413.

[6] X. Moya, L. Mañosa, A. Planes, T. Krenke, M. Acet, E.F. Wassermann, Martensitic transition and magnetic properties in $\mathrm{Ni}-\mathrm{Mn}-\mathrm{X}$ alloys, Mater. Sci. Eng. A. 438-440 (2006) 911-915. doi:10.1016/j.msea.2006.02.053.

[7] J.M. Barandiaran, V.A. Chernenko, E. Cesari, D. Salas, P. Lazpita, J. Gutierrez, I. Orue, Magnetic influence on the martensitic transformation entropy in Ni-Mn-In metamagnetic alloy, Appl. Phys. Lett. 102 (2013) 071904. doi:10.1063/1.4793412.

[8] I.D. Rodionov, Y.S. Koshkid'ko, J. Cwik, A. Quetz, S. Pandey, A. Aryal, I.S. Dubenko, S. Stadler, N. Ali, I. S. Titov, M. Blinov, M. V. Prudnikova, V.N. Prudnikov, E. Lähderanta, A.B. Granovskii, Magnetocaloric effect in Ni50Mn35In15 Heusler alloy in low and high magnetic fields, JETP Lett. 101 (2015) 6. doi:10.1134/S0021364015060107.

[9] M.G. Zavareh, C.S. Mejía, A.K. Nayak, Y. Skourski, J. Wosnitza, C. Felser, M. Nicklas, Direct measurements of the magnetocaloric effect in pulsed magnetic fields: The example of the Heusler alloy Ni50Mn35In15, Appl. Phys. Lett. 106 (2015) 071904. doi:10.1063/1.4913446.

[10] T. Krenke, E. Duman, M. Acet, E.F. Wassermann, X. Moya, L. Mañosa, A. Planes, Inverse magnetocaloric effect in ferromagnetic Ni-Mn-Sn alloys, Nat. Mater. 4 (2005) 450-454. doi:10.1038/nmat1395.

[11] C. Jing, J. Chen, Z. Li, Y. Qiao, B. Kang, S. Cao, J. Zhang, Exchange bias behavior and inverse magnetocaloric effect in Ni50Mn35In15 Heusler alloy, J. Alloys Compd. 475 (2009) 1-4. doi:10.1016/j.jallcom.2008.07.012.

[12] X. Moya, L. Mañosa, A. Planes, T. Krenke, E. Duman, M. Acet, E.F. Wassermann, Calorimetric study of the inverse magnetocaloric effect in ferromagnetic $\mathrm{Ni}-\mathrm{Mn}-\mathrm{Sn}$, J. Magn. Magn. Mater. 316 (2007) e572-e574. doi:10.1016/j.jmmm.2007.03.024.

[13] X. Moya, L. Mañosa, A. Planes, S. Aksoy, M. Acet, E.F. Wassermann, T. Krenke, Cooling and heating by adiabatic magnetization in the Ni50Mn34In16 magnetic shape memory alloy, Phys. Rev. B. 75 (2007) 184412. doi:10.1103/PhysRevB.75.184412. 
[14] E. Stern-Taulats, P.O. Castillo-Villa, L. Mañosa, C. Frontera, S. Pramanick, S. Majumdar, A. Planes, Magnetocaloric effect in the low hysteresis Ni-Mn-In metamagnetic shape-memory Heusler alloy, J. Appl. Phys. 115 (2014) 173907. doi:10.1063/1.4874935.

[15] D.M. Raj Kumar, N.V. Rama Rao, M. Manivel Raja, D.V. Sridhara Rao, M. Srinivas, S. Esakki Muthu, S. Arumugam, K.G. Suresh, Structure, magnetostructural transitions and magnetocaloric properties in Ni50-xMn37+xIn13 melt spun ribbons, J. Magn. Magn. Mater. 324 (2012) 26-32.

doi:10.1016/j.jmmm.2011.07.022.

[16] C.O. Aguilar-Ortiz, D. Soto-Parra, P. Álvarez-Alonso, P. Lázpita, D. Salazar, P.O. Castillo-Villa, H. Flores-Zúñiga, V.A. Chernenko. Influence of Fe doping and magnetic field on martensitic transition in Ni-Mn-Sn melt-spun ribbons, Acta Mater. 107 (2016) 9-16. doi:10.1016/j.actamat.2016.01.041.

[17] W. Ito, Y. Imano, R. Kainuma, Y. Sutou, K. Oikawa, K. Ishida, Martensitic and magnetic transformation behaviors in Heusler-type NiMnIn and NiCoMnIn metamagnetic shape memory alloys, Metall. Mater. Trans. A 38 (2007) 759-766. doi:10.1007/s11661-007-9094-9.

[18] S. Pandey, A. Quetz, P.J. Ibarra-Gaytan, C.F. Sanchez-Valdes, A. Aryal, I. Dubenko, D. Mazumdar, J.L. Sanchez Llamazares, S. Stadler, N. Ali, Effects of annealing on the magnetic properties and magnetocaloric effects of B doped Ni-Mn-In melt-spun ribbons, J. Alloys Compd. 731 (2018) 678-684. doi:10.1016/j.jallcom.2017.10.063.

[19] A. Planes, L. Mañosa, M. Acet, Magnetocaloric effect and its relation to shapememory properties in ferromagnetic Heusler alloys. J. Phys. Condens. Matter. 21 (2009) 233201. doi:10.1088/0953-8984/21/23/233201.

[20] J. Liu, T. Gottschall, K.P. Skokov, J.D. Moore, O. Gutfleisch, Giant magnetocaloric effect driven by structural transitions, Nat. Mater. 11 (2012) 620-626. doi:10.1038/nmat3334.

[21] Y. Yang, Z. Li, Z. Li, J. Yang, B. Yang, Y. Dong, H. Yan, Y. Zhang, C. Esling, X. Zhao, L. Zuo, Microstructural feature and magnetocaloric effect of Mn50Ni40.5In9.5 melt-spun ribbons, Crystals 7 (2017) 289. doi:10.3390/cryst7100289.

[22] J.L. Sánchez Llamazares, C. García, B. Hernando, V.M. Prida, D. Baldomir, D. Serantes, J. González. Magnetocaloric properties of as-quenched Ni50.4Mn34.9In14.7 ferromagnetic shape memory alloy ribbons, Appl. Phys. A. 103 (2011) 1125-1130. doi:10.1007/s00339-010-6053-x.

[23] Y. Zhang, Q. Zheng, W. Xia, J. Zhang, J. Du, A. Yan, Enhanced large magnetic entropy change and adiabatic temperature change of Ni43Mn46Sn11 alloys by a rapid solidification method, Scr. Mater. 104 (2015) 41-44.

doi:10.1016/j.scriptamat.2015.04.004.

[24] V. Khovaylo, M. Lyange, K. Skokov, O. Gutfleisch, R. Chatterjee, X. Xu, R. Kainuma, Adiabatic temperature change in metamagnetic Ni(Co)-Mn-Al Heusler 
alloys, Mater. Sci. Forum. 738-739 (2013) 446-450.

doi:10.4028/www.scientific.net/MSF.738-739.446.

[25] T. Gottschall, K.P. Skokov, B. Frincu, O. Gutfleisch, Large reversible magnetocaloric effect in Ni-Mn-In-Co, Appl. Phys. Lett. 106 (2015) 021901. doi:10.1063/1.4905371.

[26] I. Titov, M. Acet, M. Farle, D. González-Alonso, L. Mañosa, A. Planes, T. Krenke, Hysteresis effects in the inverse magnetocaloric effect in martensitic Ni-Mn-In and Ni-Mn-Sn, J. Appl. Phys. 112 (2012) 0739141. doi:10.1063/1.4757425.

[27] A.M. Aliev, A.B. Batdalov, I.K. Kamilov, V.V. Koledov, V.G. Shavrov, V.D. Buchelnikov, J. García, V.M. Prida, B. Hernando, Magnetocaloric effect in ribbon samples of Heusler alloys Ni-Mn-M (M=In, Sn), Appl. Phys. Lett. 97 (2012) 212505. doi:10.1063/1.3521261.

[28] P. Álvarez-Alonso, C.O. Aguilar-Oritz, J.P. Camarillo, D. Salazar, H. Flores-Zúñiga, V.A. Chernenko, Adiabatic magnetocaloric effect in Ni50Mn35In15 ribbons, Appl. Phys. Lett. 109 (2016) 212402. doi:10.1063/1.4968592.

[29] J.L. Sánchez Llamazares, B. Hernando, C. García, J. González, L. Escoda, J.J. Suñol, Martensitic transformation in Ni50.4Mn34.9In14.7 melt spun ribbons, J. Phys. D. Appl. Phys. 42 (2009) 045002. doi:10.1088/0022-3727/42/4/045002.

[30] S.C. Ma, C.W. Shih, J. Liu, J.H. Yuan, S.Y. Lee, Y.I. Lee, H.W. Chang, W.C. Chang, Wheel speed-dependent martensitic transformation and magnetocaloric effect in Ni-Co-Mn-Sn ferromagnetic shape memory alloy ribbons, Acta Mater. 90 (2015) 292-302. doi:10.1016/j.actamat.2015.03.011.

[31] R. Das, P. Saravanan, D. Arvindha Babu, A. Perumal, A. Srinivasan, Influence of solidification rate and heat treatment on magnetic refrigerant properties of melt spun Ni51Mn34In14Si 1 ribbons, J. Magn. Magn. Mater. 344 (2013) 152-157. doi:10.1016/j.jmmm.2013.05.053.

[32] A. Quintana-Nedelcos, J.L. Sánchez-Llamazares, D. Ríos-Jara, A.G. LaraRodríguez, T. García-Fernández, Effect of quenching rate on the average grain size and martensitic transformation temperature in rapidly solidified polycrystalline Ni50Mn37Sn13 alloy ribbons, Phys. Status Solidi. 210 (2013) 2159-2165. doi:10.1002/pssa.201329146.

[33] V.I. Tkatch, A.I. Limanovskii, S.N. Denisenko, S.G. Rassolov, The effect of the melt-spinning processing parameters on the rate of cooling, Mater. Sci. Eng. A. 323 (2002) 91-96. doi:10.1016/S0921-5093(01)01346-6.

[34] V.A. Chernenko, E. Cesari, J. Pons, C. Seguí, Phase transformations in rapidly quenched Ni - Mn - Ga alloys, J. Mater Res. 15 (2000) 1496-1504. doi:https://doi.org/10.1557/JMR.2000.0215.

[35] H.C. Xuan, K.X. Xie, D.H. Wang, Z.D. Han, C.L. Zhang, B.X. Gu, Y.W. Du, Effect of annealing on the martensitic transformation and magnetocaloric effect in Ni44.1Mn44.2Sn11.7 ribbons, Appl. Phys. Lett. 92 (2008) 242506. 
doi:10.1063/1.2948904.

[36] T. Krenke, M. Acet, E.F. Wassermann, X. Moya, L. Mañosa, A. Planes, Martensitic transitions and the nature of ferromagnetism in the austenitic and martensitic states of Ni-Mn-Sn alloys, Phys. Rev. B 72 (2005) 014412.

doi:10.1103/PhysRevB.72.014412.

[37] J. Rodríguez-Carvajal, Recent advances in magnetic structure determination by neutron powder diffraction, Phys. B Condens. Matter. 192 (1993) 55-69. doi:10.1016/0921-4526(93)90108-I.

[38] E. Petrovský, A. Kapička, On determination of the Curie point from thermomagnetic curves, J. Geophys. Res. Solid Earth. 111 (2006) B12S27. doi:10.1029/2006JB004507.

[39] P. Álvarez-Alonso, J. López-García, G. Daniel-Perez, D. Salazar, P. Lázpita, J.P. Camarillo, H. Flores-Zuñiga, D. Rios-Jara, J.L. Sánchez-Llamazares, V.A.

Chernenko, Simple Set-Up for Adiabatic Measurements of Magnetocaloric Effect, Key Eng. Mater. 644 (2015) 215-218. doi:10.4028/www.scientific.net/KEM.644.215.

[40] J. Pons, V.A. Chernenko, R. Santamarta, E. Cesari, Crystal structure of martensitic phases in Ni-Mn-Ga shape memory alloys, Acta Mater. 48 (2000) 3027-3038. doi:10.1016/S1359-6454(00)00130-0.

[41] T. Miyamoto, W. Ito, R.Y. Umetsu, R. Kainuma, T. Kanomata, K. Ishida, Phase stability and magnetic properties of Ni50Mn50-xInx Heusler-type alloys, Scr. Mater. 62 (2010) 151-154. doi:10.1016/j.scriptamat.2009.10.006.

[42] J. Liu, T.G. Woodcock, N. Scheerbaum, O. Gutfleisch, Influence of annealing on magnetic field-induced structural transformation and magnetocaloric effect in $\mathrm{Ni}-$ Mn-In-Co ribbons, Acta Mater. 57 (2009) 4911-4920. doi:10.1016/j.actamat.2009.06.054.

[43] H.C. Xuan, P.D. Han, D.H. Wang, Y.W. Du, The influence of Ge substitution on the magnetostucture transition and magnetocaloric effect of $\mathrm{Mn}-\mathrm{Ni}-\mathrm{Sn}-\mathrm{Ge}$ alloys, J. Alloys Compd. 582 (2014) 369-373. doi:10.1016/j.jallcom.2013.08.053.

[44] Z. Li, J. Wang, Y. Zhang, K. He, X. Zhao, L. Zuo, G. Hofer, C. Esling, Texturation of Ni-Co-Mn-In ribbons by melt spinning, Adv. Eng. Mater. 12 (2010) 1024-1028. doi:10.1002/adem.201000073.

[45] V. Recarte, J.I. Perez-Landazabal, V. Sánchez-Alarcos, J.A. Rodríguez-Velamazán, Dependence of the martensitic transformation and magnetic transition on the atomic order in $\mathrm{Ni}$ - Mn - In metamagnetic shape memory alloys, Acta Mater. 60 (2012) 1937-1945. doi:10.1016/j.actamat.2012.01.020.

[46] V.A. Chernenko, J.M. Barandiarán, J. Rodriguez Fernández, D.P. Rojas, J. Gutiérrez, P. Lázpita, I. Orue. Magnetic and magnetocaloric properties of martensitic Ni2Mn1.4Sn0.6 Heusler alloy, J. Magn. Magn. Mater. 324 (2012) 3519-3523. doi:10.1016/j.jmmm.2012.02.080. 
[47] J.L. Sánchez Llamazares, H. Flores-Zúñiga, D. Ríos-Jara, C.F. Sánchez-Valdes, T. García-Fernández, C. A. Ross, C. García, Structural and magnetic characterization of the intermartensitic phase transition in NiMnSn Heusler alloy ribbons, J. Appl. Phys. 113 (2013) 17A948. doi:10.1063/1.4800836.

[48] J. Nogués, I.K. Schuller, Exchange bias, J. Mag. Mag. Mater. 192 (1999) 203-232. doi:10.1016/S0304-8853(98)00266-2.

[49] Y.H. Qu, D.Y. Cong, Z. Chen, W.Y. Gui, X.M. Sun, S.H. Li, L. Ma, Y.D. Wang, Large and reversible inversemagnetocaloric effect in Ni48.1Co2.9Mn35.0In14.0 metamagnetic shape memory microwire, Appl. Phys. Lett. 111 (2017) 192412.

[50] A.L. Greer, Crystallisation kinetics of Fe80B20 glass, Acta Metall. 30 (1982) 171192. doi:10.1016/0001-6160(82)90056-6.

[51] J. Ortín, A. Planes, L. Delaey, Hysteresis in Shape-Memory Materials, in: G. Bertotti, I.D. Mayergoyz (Eds.), The Science of Hysteresis: Hysteresis in materials, first ed., Gulf Professional Publishing, 2006, pp. 467-553. doi:http://dx.doi.org/10.1016/B978-012480874-4/50023-3.

[52] E. Barmina, A. Kosogor, V. Khovaylo, M. Gorshenkov, M. Lyange, D. Kuchin, E. Dilmieva, V. Koledov, V. Shavrov, S. Taskaev, R. Chatterjee, L.K. Varga, Thermomechanical properties and two-way shape memory effect in melt spun Ni57Mn21Al21Si1 ribbons, J. Alloys Compd. 695 (2017) 310-314. doi:10.1016/j.jallcom.2016.11.311.

[53] W-H. Wang, J-L. Chen, Z-H. Liu, G-H. Wu, W-S. Zhan, Thermal hysteresis and friction of phase boundary motion in ferromagnetic Ni52Mn23Ga25 single crystals, Phys. Rev. B 65 (2001) 012416. doi:10.1103/PhysRevB.65.012416.

[54] C.N. Saikrishna, K.V. Ramaiah, J. Bhagyaraj, Gouthama, S.K. Bhaumik, Influence of stored elastic strain energy on fatigue behaviour of NiTi shape memory alloy thermal actuator wire, Mater. Sci. Eng. A. 587 (2013) 65-71. doi:10.1016/j.msea.2013.08.048.

[55] V.A. L'vov, A. Kosogor, J.M. Barandiaran, V.A. Chernenko, Destabilization of Ni Mn - Ga martensite : Experiment and theory, Acta Mater. 60 (2012) 1587-1593. doi:10.1016/j.actamat.2011.11.040.

[56] A.R. Pelton, G.H. Huang, P. Moine, R. Sinclair, Effects of thermal cycling on microstructure and properties in Nitinol, Mater. Sci. Eng. A. 532 (2012) 130-138. doi:10.1016/j.msea.2011.10.073.

[57] N.M. Bruno, Y.J. Huang, C.L. Dennis, J.G. Li, R.D. Shull, J.H. Ross Jr, Y. I. Chumlyakov, I. Karaman, Effect of grain constraint on the field requirements for magnetocaloric effect in Ni45Co5Mn40Sn10 melt-spun ribbons, J. Appl. Phys. 120 (2016) 075101. doi:10.1063/1.4960353.

[58] P. Álvarez-Alonso, C.O. Aguilar-Ortiz, E. Villa, A. Nespoli, H. Flores-Zúñiga, V.A. Chernenko, Conventional and inverse elastocaloric effect in Ni-Fe-Ga and Ni-Mn-Sn ribbons, Scr. Mater. 128 (2017) 36-40. doi:10.1016/j.scriptamat.2016.09.033. 
[59] Y.H. Qu, D.Y. Cong, X.M. Sun, Z.H. Nie, W.Y. Gui, R.G. Li, Y. Ren, Y.D. Wang, Giant and reversible room-temperature magnetocaloric effect in Ti-doped Ni-CoMn-Sn magnetic shape memory alloys, Acta Mater. 134 (2017) 236-248. doi:10.1016/j.actamat.2017.06.010.

[60] L. Huang, D.Y. Cong, H.L. Suo, Y.D. Wang, Giant magnetic refrigeration capacity near room temperature in Ni40Co10Mn40Sn10 multifunctional alloy, Appl. Phys. Lett. 104 (2014) 132407. doi:10.1063/1.4870771.

[61] J.M. Barandiaran, V.A. Chernenko, E. Cesari, D. Salas, J. Gutierrez, P. Lazpita. Magnetic field and atomic order effect on the martensitic transformation of a metamagnetic alloy, J. Phys.: Condens. Matter 25 (2013) 484005 (6pp). doi: doi.org/10.1088/0953-8984/25/48/484005

[62] D. Bourgault, L. Porcar, S. Rivoirard, P. Courtois, V. Hardy. Entropy change of a Ni45.5Co4.5Mn37In13 single crystal studied by scanning calorimetry in high magnetic fields: Field dependence of the magnetocaloric effect, Appl. Phys. Lett. 107 (2015) 092403; https://doi.org/10.1063/1.4929950

[63] K.A. Gschneidner Jr., V.K. Pecharsky, A.O. Pecharsky, C.B. Zimm, Recent developments in magnetic refrigeration, Mater. Sci. Forum. 315-317 (1999) 69-76. doi:10.4028/www.scientific.net/MSF.315-317.69.

[64] W. Wang, H. Li, J. Ren, J. Fu, Q. Zhai, Z. Luo, H. Zheng, Enhanced magnetocaloric properties in annealed Heusler Ni-Mn-Sn ribbons, J. Magn. Magn. Mater. 374 (2015) 153-156. doi:10.1016/j.jmmm.2014.08.042. 


\section{Table 1}

Martensitic transformation characteristic temperatures ( $T_{\mathrm{MS}}, T_{M F}$ and $T_{\mathrm{AS}}, T_{\mathrm{AF}}$ stand for martensite and austenite start and finish temperatures, respectively, $T_{0}$ is a middle hysteresis temperature); average transformation enthalpies $(\Delta H)$ and entropies $(\Delta S)$ obtained from the DSC curves; Curie temperature of martensite $\left(T_{\mathrm{C}}{ }^{\mathrm{M}}\right)$ and austenite $\left(T_{\mathrm{C}}{ }^{\mathrm{A}}\right)$ estimated from the $M(T)$ dependences; thickness $(d)$; grain size (GS); L2 1 proportion and cubic lattice parameters of the L2 1 and B2 structures at $333 \mathrm{~K}$; and the sensitivity of MT temperature to the applied magnetic field $\left(\mathrm{d} T_{0} / \mu_{0} \mathrm{~d} H\right)$ for $\mathrm{Ni}_{50} \mathrm{Mn}_{35} \mathrm{In}_{15}$ ribbons fabricated at different linear wheel speed (WS) of the copper wheel.

\begin{tabular}{|c|c|c|c|c|c|c|c|c|c|c|c|c|c|c|c|c|}
\hline \multirow[t]{2}{*}{ Ribbon } & WS & $T_{\mathrm{MS}}$ & $T_{\mathrm{MF}}$ & $T_{\mathrm{AS}}$ & $T_{\mathrm{AF}}$ & $T_{0}$ & $T_{\mathrm{C}^{\mathrm{M}}}^{\mathrm{M}}$ & $T_{\mathrm{C}}{ }^{\mathrm{A}}$ & $|\Delta H|$ & $|\Delta S|$ & $d$ & GS & $\mathrm{L} 2{ }_{1}$ & $\mathrm{a}_{0}\left(\mathrm{~L} 2_{1}\right)$ & $\mathrm{a}_{0}(\mathrm{~B} 2)$ & $\mathrm{d} T_{0} / \mu_{0} \mathrm{dH}$ \\
\hline & $\mathrm{m} / \mathrm{s}$ & $\mathrm{K}$ & $\mathrm{K}$ & K & $\mathrm{K}$ & K & $\mathrm{K}$ & $\mathrm{K}$ & $\mathrm{J} / \mathrm{g}$ & $\mathrm{J} / \mathrm{kgK}$ & $\mu \mathrm{m}$ & $\mu \mathrm{m}$ & $\%$ & $\mathrm{~nm}$ & $\mathrm{~nm}$ & $\mathrm{~K} / \mathrm{T}$ \\
\hline V10 & 10 & 293 & 280 & 297 & 304 & 300 & 199 & 309 & 8.2 & 27.7 & 50 & 7.3 & 84.5 & 0.6006 & 0.3012 & -2.2 \\
\hline V20 & 20 & 289 & 273 & 290 & 300 & 294 & 197 & 306 & 7.6 & 26.2 & 23 & 5.5 & 23.4 & 0.6012 & 0.3009 & -2.4 \\
\hline V30 & 30 & 282 & 271 & 287 & 295 & 289 & 180 & 295 & 7.4 & 25.8 & 13 & 3.0 & 4.5 & 0.6014 & 0.3009 & - \\
\hline V40 & 40 & 279 & 266 & 285 & 294 & 286 & 177 & 295 & 6.9 & 24.0 & 12 & 2.2 & $\sim 0$ & - & 0.3002 & -2.0 \\
\hline V50 & 50 & 278 & 264 & 282 & 292 & 285 & 178 & 293 & 6.5 & 23.0 & 12 & 0.9 & $\sim 0$ & - & 0.3002 & -1.7 \\
\hline
\end{tabular}


Figure captions

Fig. 1. X-ray powder diffraction patterns collected at $333 \mathrm{~K}$ for $\mathrm{Ni}_{50} \mathrm{Mn}_{35} \mathrm{In}_{15}$ as-spun ribbons at different wheel speed shown in $\mathrm{m} / \mathrm{s}$ at the right side of curves.

Fig. 2 Microstructure of $\mathrm{Ni}_{50} \mathrm{Mn}_{35} \mathrm{In}_{15}$ as-spun ribbons: free side surface of V10 (a), V30 (b) and V50 (c) at $323 \mathrm{~K}$; and contact side surface of V10 at $223 \mathrm{~K}$ (d).

Fig. 3 Thickness and grain size in $\mathrm{Ni}_{50} \mathrm{Mn}_{35} \mathrm{In}_{15}$ as-spun ribbons fabricated at different wheel speed. Inset: optical image of the cross-section of V50 ribbon.

Fig. 4. DSC curves for $\mathrm{Ni}_{50} \mathrm{Mn}_{35} \mathrm{In}_{15}$ as-spun ribbons prepared with different wheel speed variating from 10 to $50 \mathrm{~m} / \mathrm{s}$. Inset shows the characteristic MT temperature, $T_{0}$, and transformation entropy, $\Delta \mathrm{S}$, as a function of wheel speed. Dashed and dash-dotted lines are guides for the eye.

Fig. 5 (a) Zero-field (ZFC), field cooling/heating (FC/FH) magnetization curves measured at low applied magnetic field $(10 \mathrm{mT})$ for $\mathrm{Ni}_{50} \mathrm{Mn}_{35} \mathrm{In}_{15}$ as-spun ribbons. Insets presents the dependence of splitting $\Delta M$ between ZFC and FC-FH curves at $5 \mathrm{~K}$.(b) Thermomagnetization curves for the V50 as-spun ribbon under constant applied magnetic fields.

Fig. 6. Isothermal magnetization hysteresis loops for V10 (a) and V50 (b) ribbons at $5 \mathrm{~K}$ and $20 \mathrm{~K}$. (c) Variation of $H_{\mathrm{E}}$ and $H_{\mathrm{C}}$ as a function of the temperature in FC regime of $\mathrm{Ni}_{50} \mathrm{Mn}_{35} \mathrm{In}_{15}$ as-spun ribbons. The data for the bulk alloy were adapted from Ref. [11].

Fig. 7. Magnetic field-induced adiabatic temperature change under $\mu_{0} \Delta H=1.95 \mathrm{~T}$ at different temperatures during step-like cooling/heating for $\mathrm{Ni}_{50} \mathrm{Mn}_{35} \mathrm{In}_{15}$ as-spun ribbons obtained at the three different solidification rates (wheel speeds). Dotted (cooling) and dashed (heating) lines are guides for the eye.

Fig. 8. Temperature dependence of the magnetic entropy change under different applied magnetic fields for (a) V10 and (b) V50 ribbons; magnetic field dependence of the maximum 
entropy change $\Delta S_{\mathrm{M}}(T)$ (c) and the relative cooling power (d) associated with the reverse MT (heating) for ribbons fabricated by different wheel speed. 


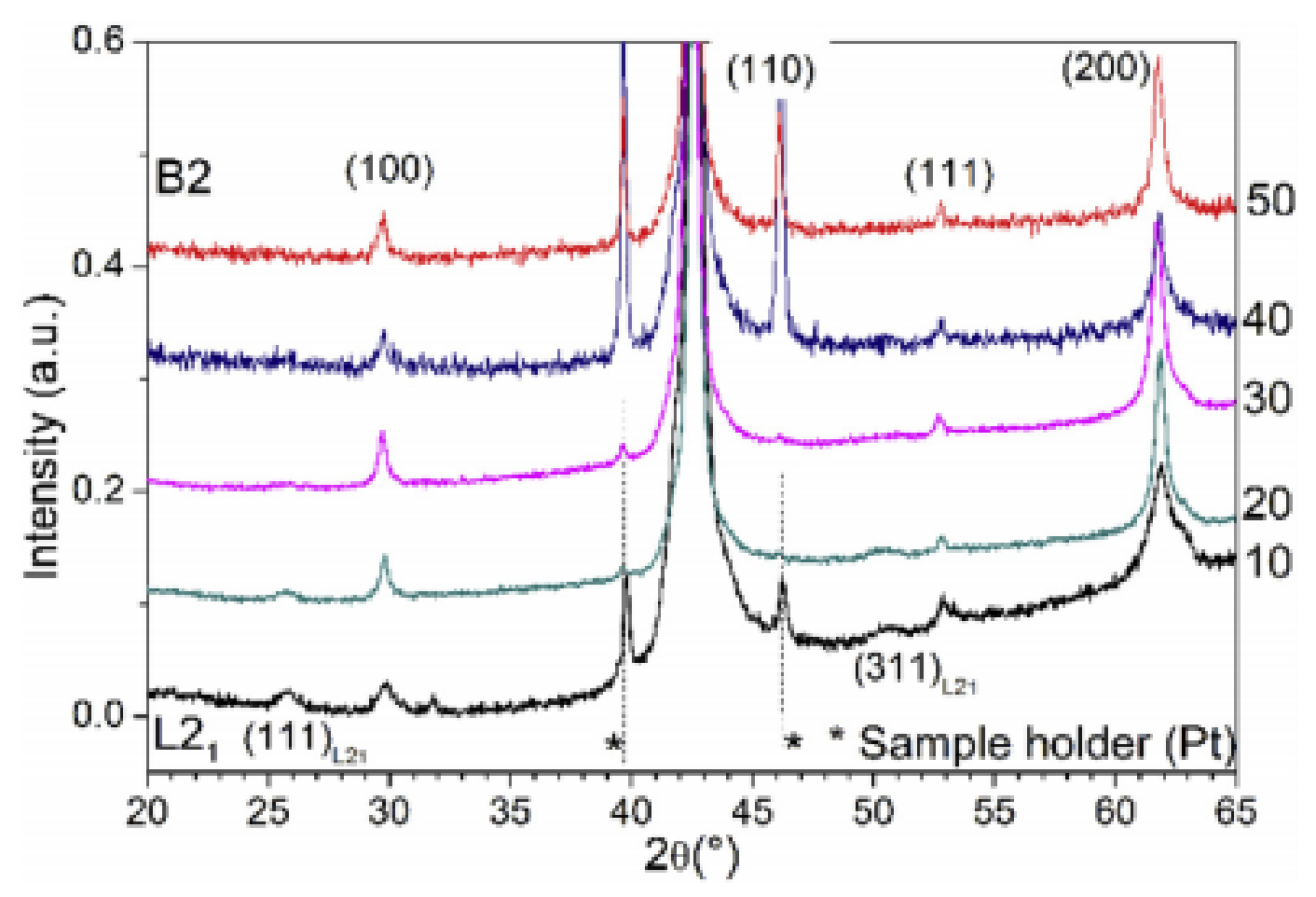

Fig. 1. X-ray powder diffraction patterns collected at $333 \mathrm{~K}$ for $\mathrm{Ni}_{50} \mathrm{Mn}_{35} \mathrm{In}_{15}$ as-spun ribbons at different wheel speed shown in $\mathrm{m} / \mathrm{s}$ at the right side of curves. 

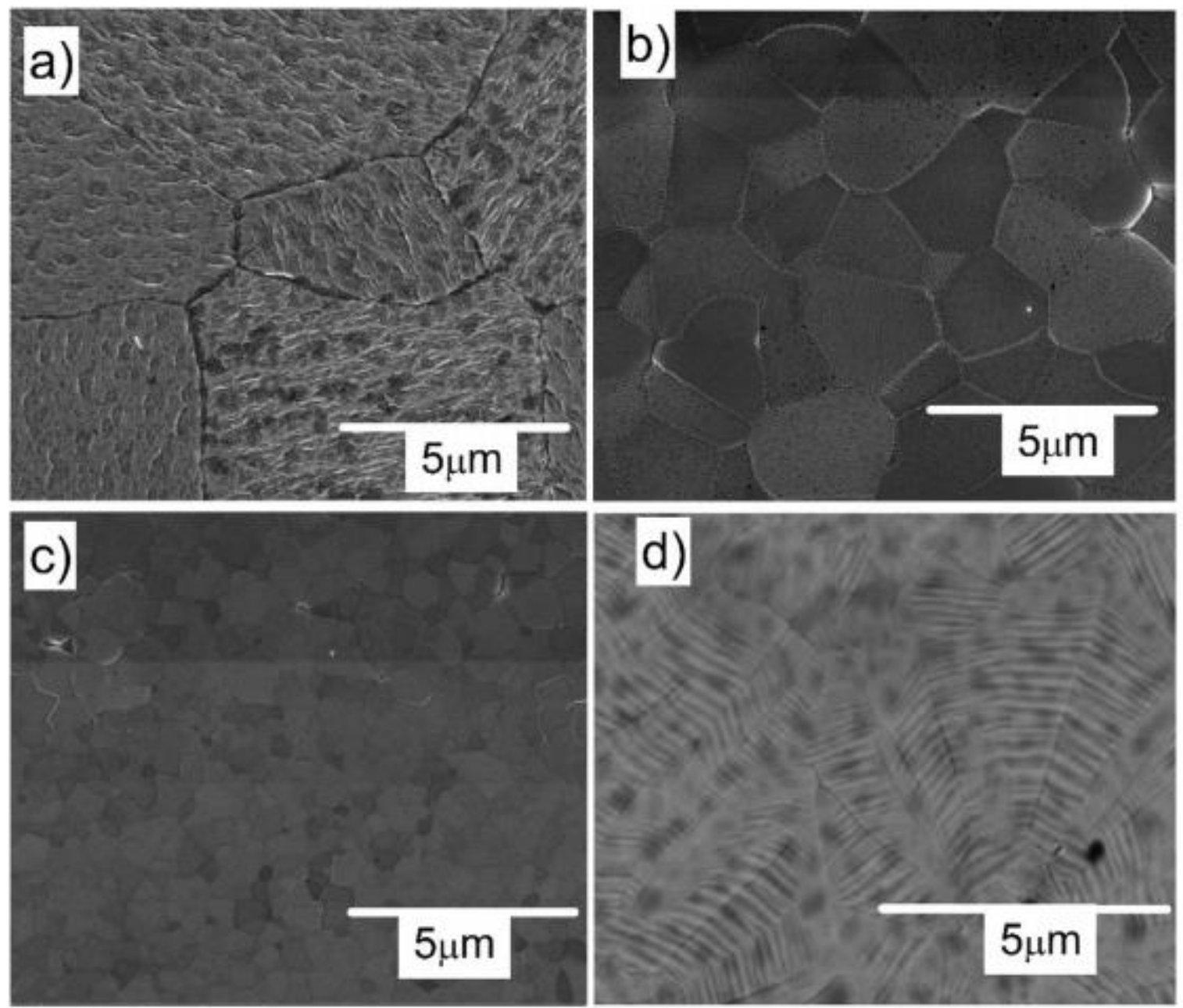

Fig. 2 Microstructure of Ni50Mn35In15 as-spun ribbons: free side surface of V10 (a), V30 (b) and V50 (c) at $323 \mathrm{~K}$; and contact side surface of V10 at $223 \mathrm{~K}$ (d). 


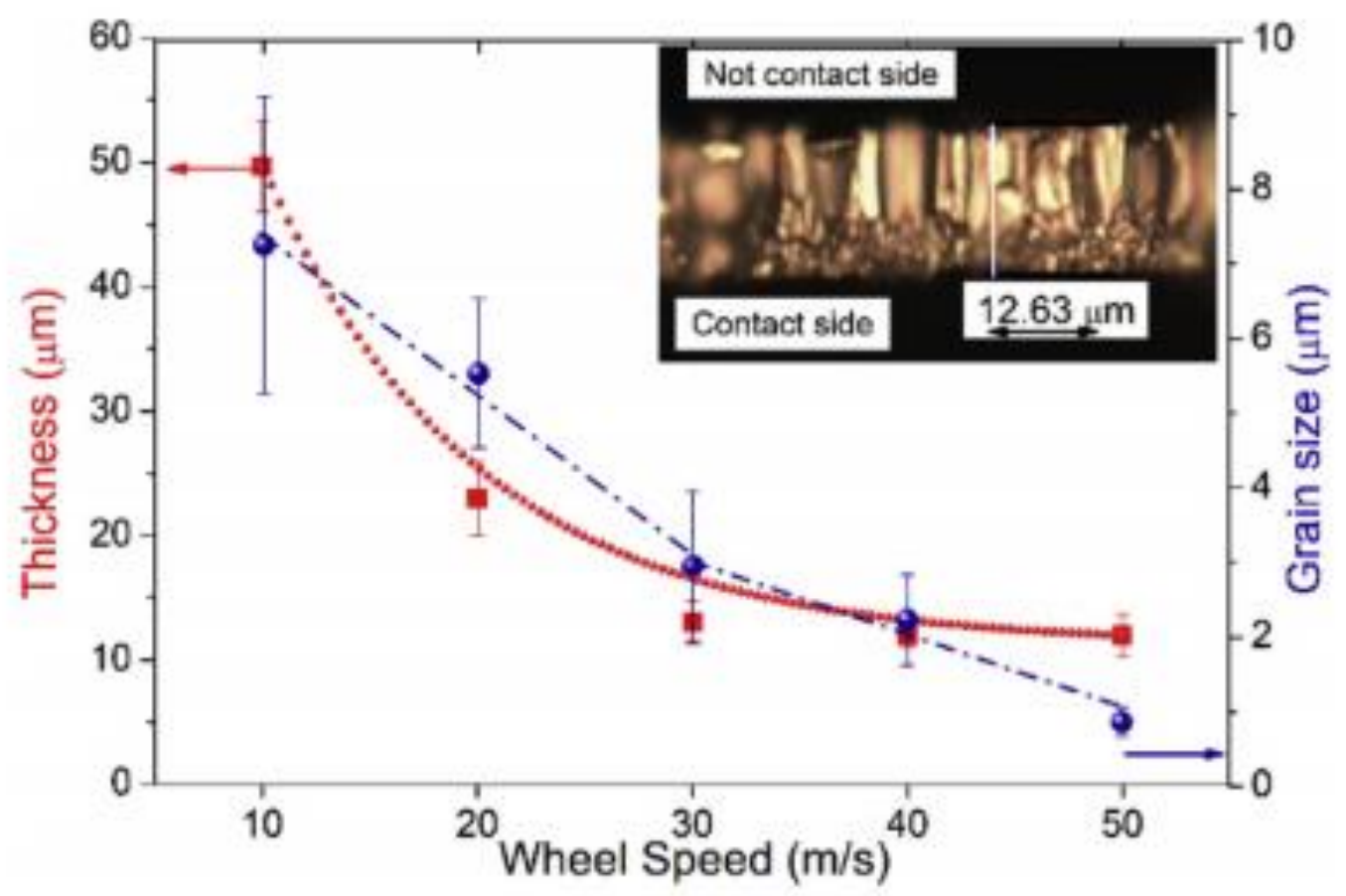

Fig.3 Thickness and grain size in $\mathrm{Ni}_{50} \mathrm{Mn}_{35} \mathrm{In}_{15}$ as-spun ribbons fabricated at different wheel speed. Inset: optical image of the cross-section of V50 ribbon. 


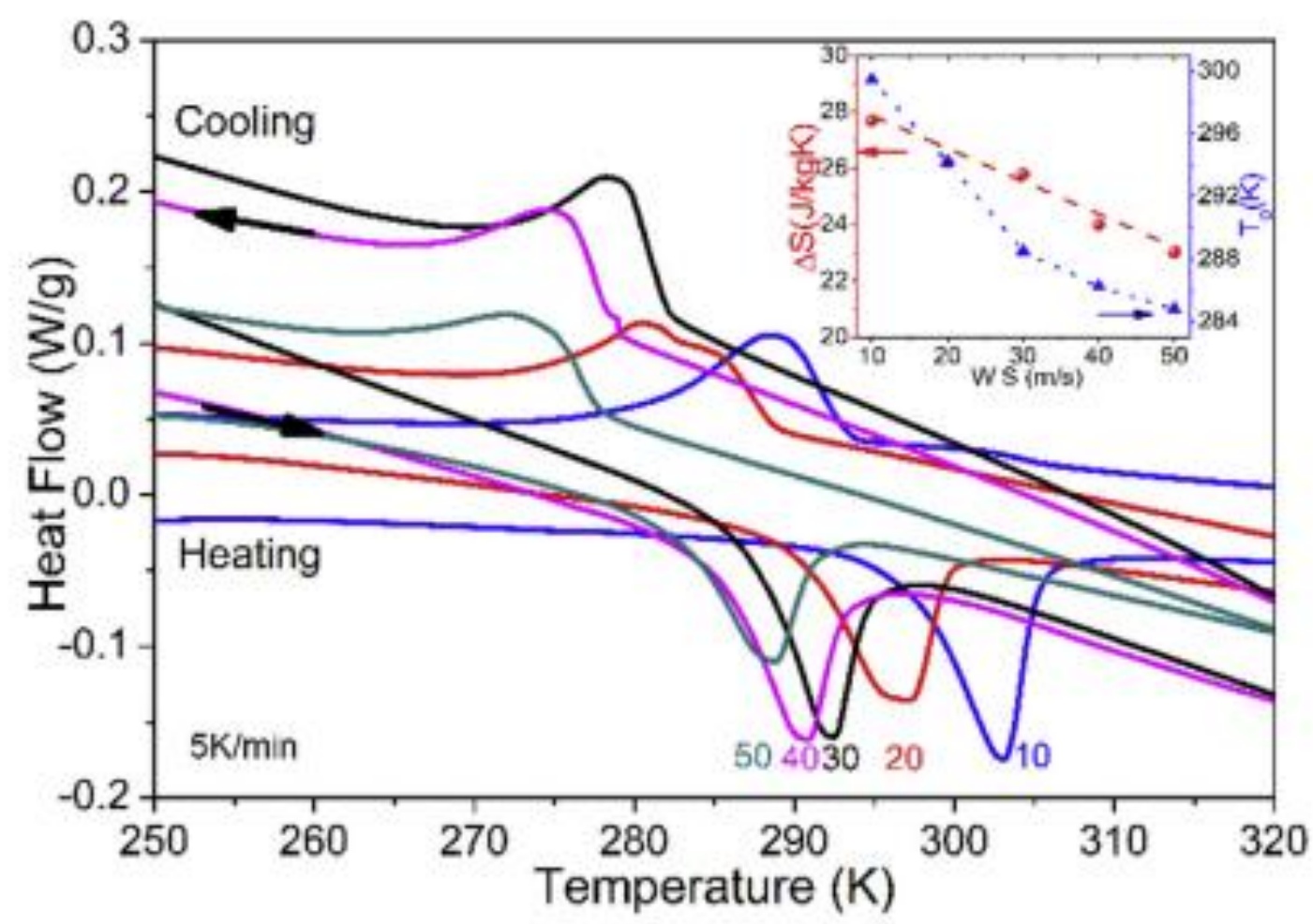

Fig. 4. DSC curves for $\mathrm{Ni}_{50} \mathrm{Mn}_{35} \mathrm{In}_{15}$ as-spun ribbons prepared with different wheel speed variating from 10 to $50 \mathrm{~m} / \mathrm{s}$. Inset shows the characteristic MT temperature, $T_{0}$, and transformation entropy, $\Delta \mathrm{S}$, as a function of wheel speed. Dashed and dash-dotted lines are guides for the eye. 

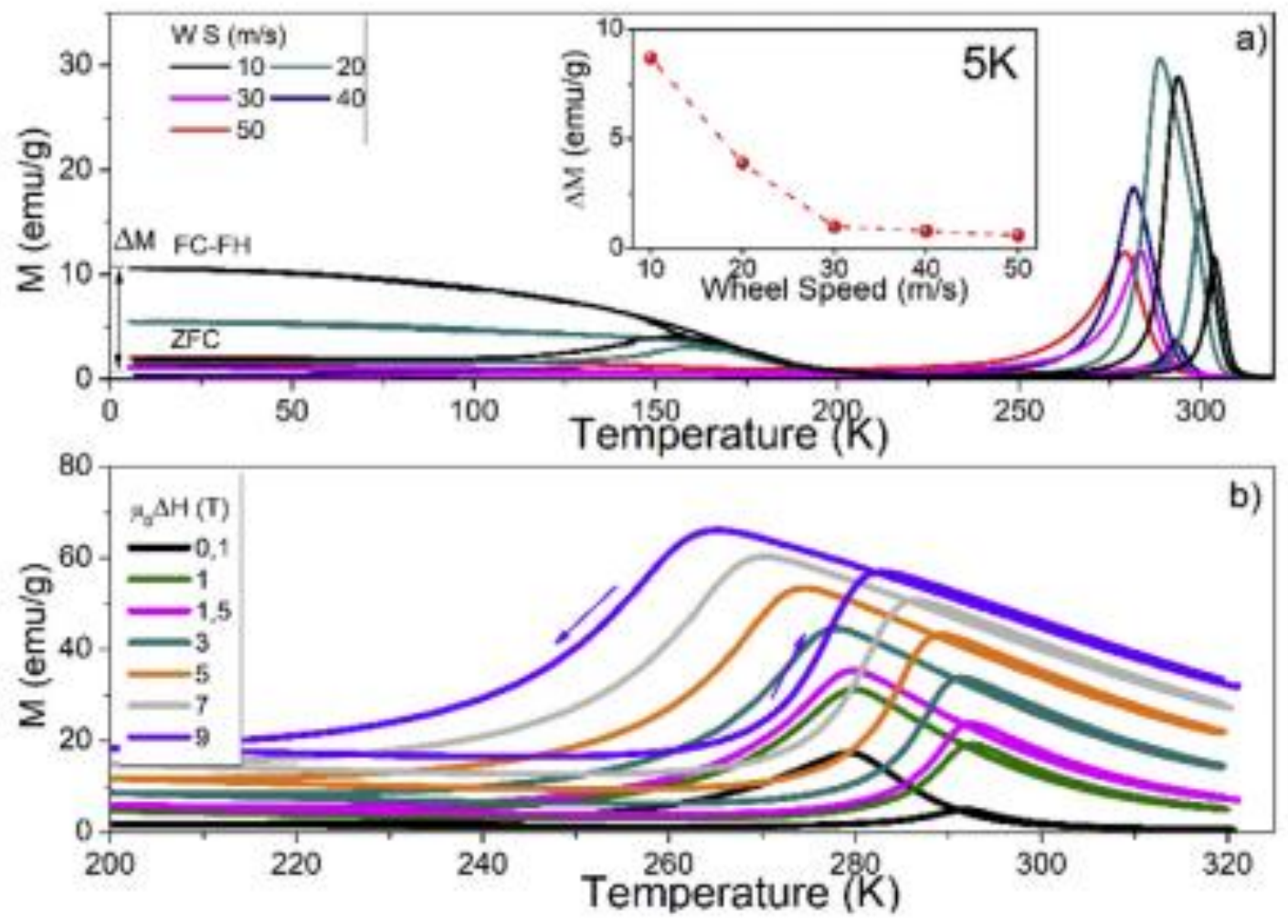

Fig. 5 (a) Zero-field (ZFC), field cooling/heating (FC/FH) magnetization curves measured at low applied magnetic field $(10 \mathrm{mT})$ for $\mathrm{Ni}_{50} \mathrm{Mn}_{35} \mathrm{In}_{15}$ as-spun ribbons. Insets presents the dependence of splitting $\triangle M$ between ZFC and FC-FH curves at 5K.(b) Thermomagnetization curves for the V50 as-spun ribbon under constant applied magnetic fields. 

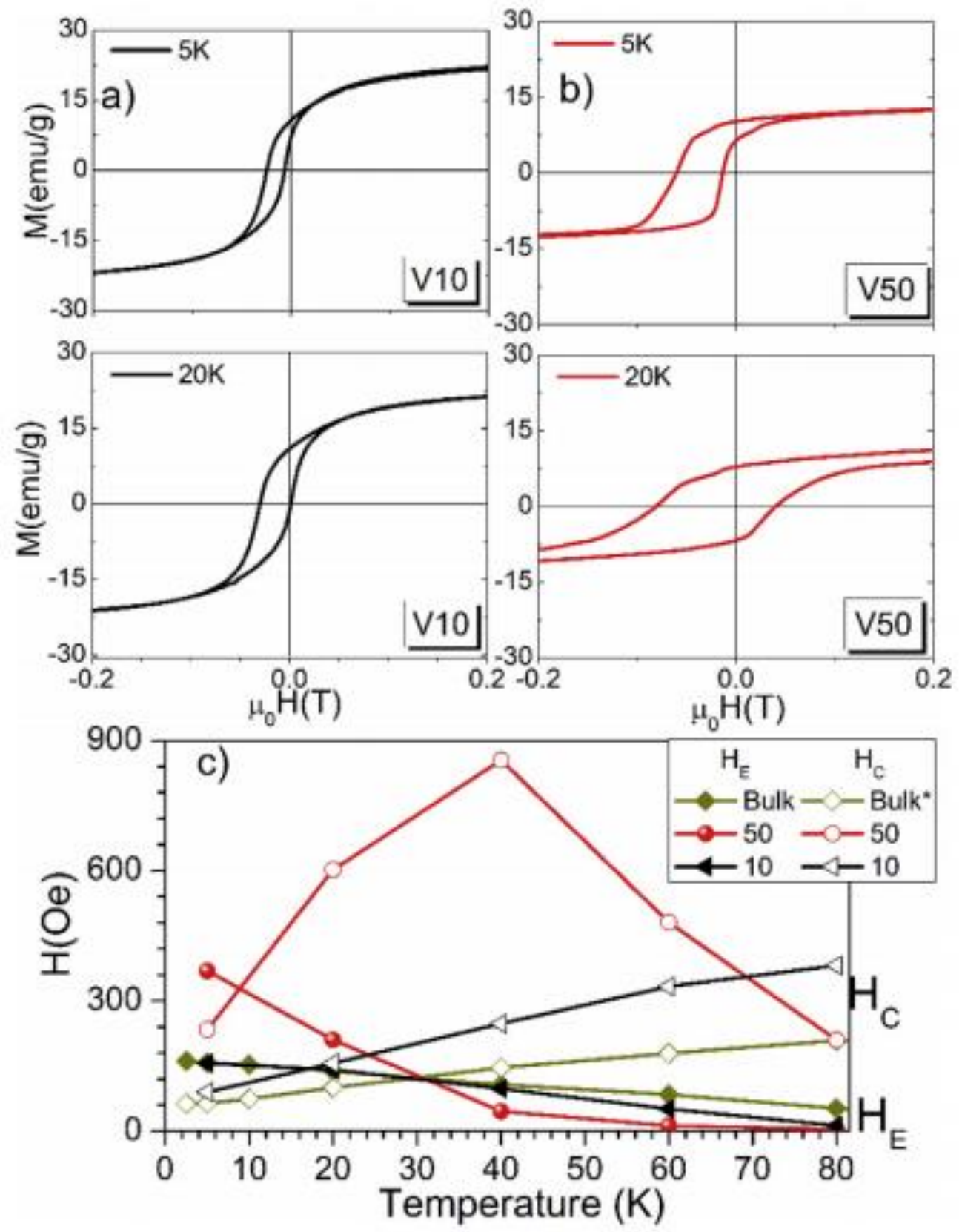

Fig. 6. Isothermal magnetization hysteresis loops for V10 (a) and V50 (b) ribbons at $5 \mathrm{~K}$ and $20 \mathrm{~K}$. (c) Variation of $H_{\mathrm{E}}$ and $H_{\mathrm{C}}$ as a function of the temperature in $\mathrm{FC}$ regime of $\mathrm{Ni}_{50} \mathrm{Mn}_{35} \mathrm{In}_{15}$ as-spun ribbons. The data for the bulk alloy were adapted from Ref. [11]. 


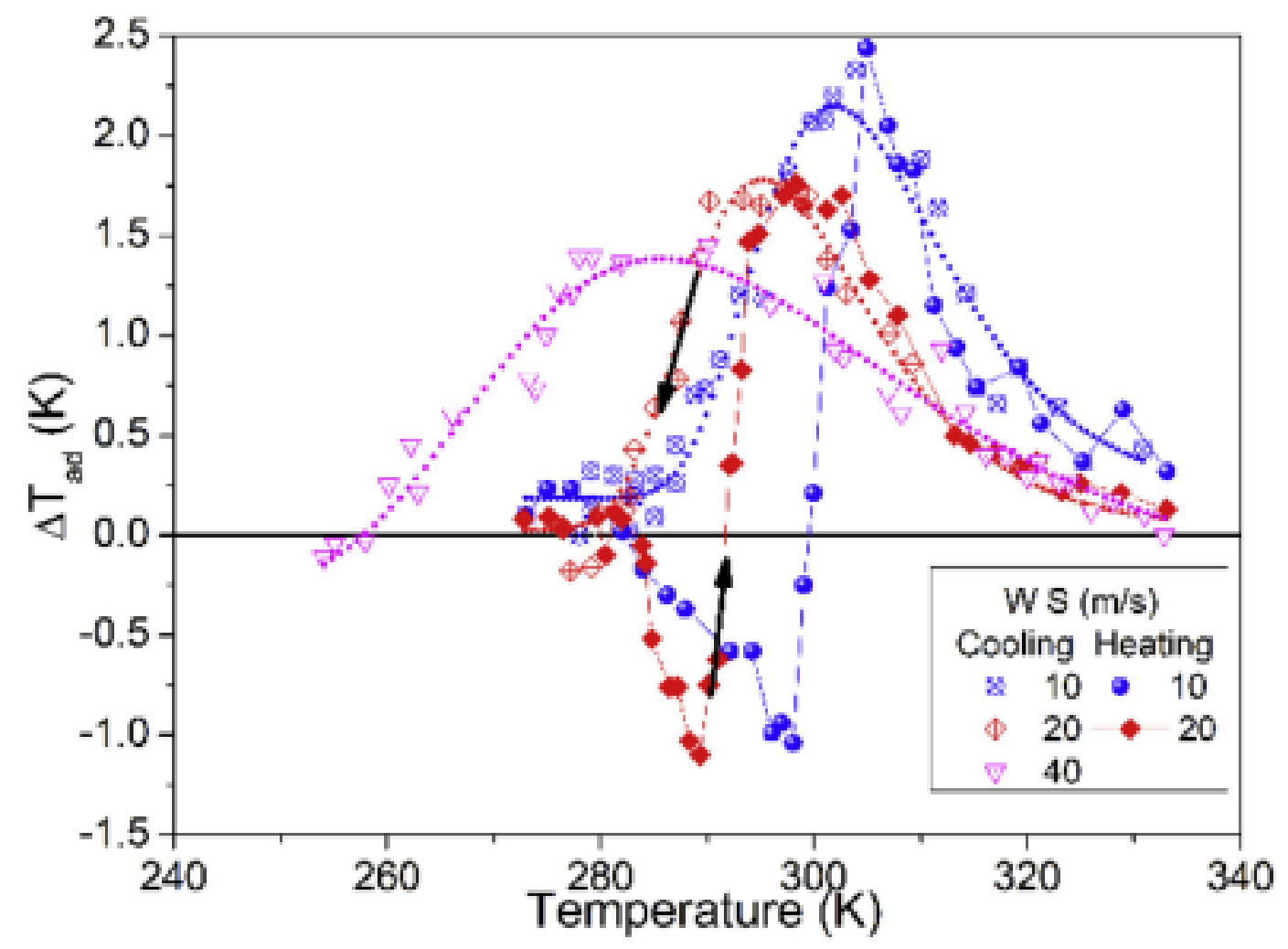

Fig. 7. Magnetic field-induced adiabatic temperature change under $\mu_{0} \Delta H=1.95 \mathrm{~T}$ at different temperatures during step-like cooling/heating for $\mathrm{Ni}_{50} \mathrm{Mn}_{35} \mathrm{In}_{15}$ as-spun ribbons obtained at the three different solidification rates (wheel speeds). Dotted (cooling) and dashed (heating) lines are guides for the eye. 

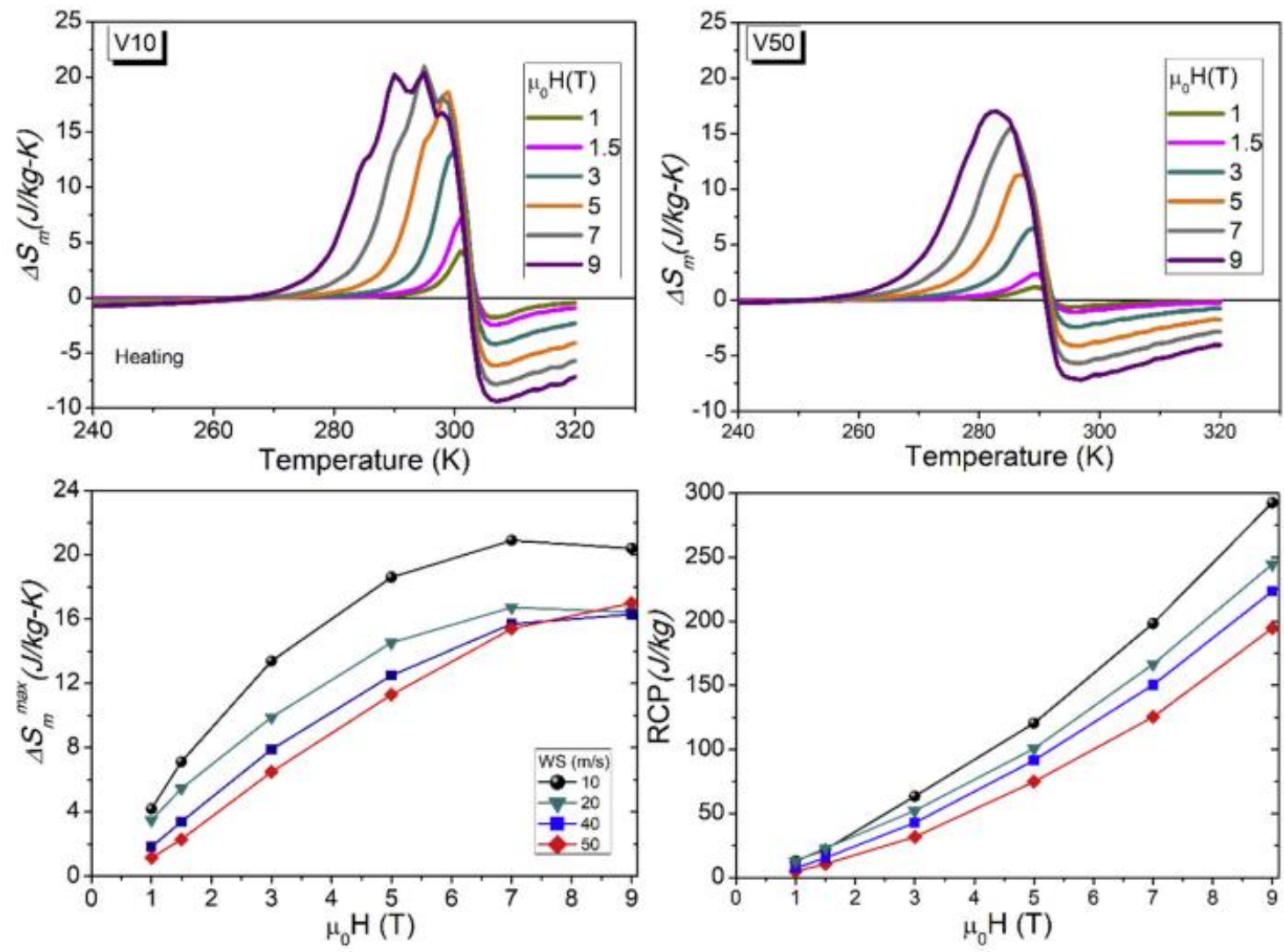

Fig. 8. Temperature dependence of the magnetic entropy change under different applied magnetic fields for (a) V10 and (b) V50 ribbons; magnetic field dependence of the maximum entropy change $\Delta S_{\mathrm{M}}(T)$ (c) and the relative cooling power (d) associated with the reverse MT (heating) for ribbons fabricated by different wheel speed. 